\title{
Hedonic Models and Air Pollution: Twenty-Five Years and Counting*
}

\author{
V. KERRY SMITH ${ }^{1}$ and JU CHIN HUANG ${ }^{2}$ \\ ${ }^{1}$ Resource and Environmental Economics Program, North Carolina State University, Raleigh, \\ N.C. 27695, and Resources for the Future, Washington, D.C. 20036; ${ }^{2}$ Resource and Environ- \\ mental Economics Program, North Carolina State University, Raleigh, N.C. 27695 and Dept. of \\ Economics, East Carolina University, Greenville, N.C. 27858
}

\begin{abstract}
This paper reports a meta analysis of how effectively hedonic property models have detected the influence of air pollution on housing prices. Probit estimates are reported describing how data, model specification, and local property market conditions in cities represented in thirty-seven studies influence the ability of hedonic models to uncover negative, statistically significant relationships between housing prices and air pollution measures.
\end{abstract}

Key words. Hedonic models, air pollution, meta analysis.

\section{Introduction}

A little over twenty-five years ago, Ridker and Henning (1967) reported the first application of hedonic methods to estimate the effect of air pollution on property values in St. Louis. Using 1960 census data for tracts where at least 60 percent of the housing units were single family units and the population density was at least one person per acre, these authors found ". . . an estimate for the effect of air pollution on residential property values ... that can be used with some confidence" (p. 256). The authors investigated two pollution variables - a measure for sulfates and one for suspended particulates. They focused their analysis on the first measure because the estimates with the suspended particulate measure were judged to be "unsatisfactory" (they yielded positive coefficient estimates). By finding a negative relationship between property values and sulfate measures, Ridker and Henning's research motivated the conceptual models of Rosen (1974) and Freeman (1974) almost a decade later and helped to establish the hedonic approach for estimating people's values for site-specific amenities (see Palmquist, 1991 for a review of hedonic methods).

This paper considers the question that started all of this activity from the vantage point of twenty-five years of experience. Now that Ridker and Henning's proposal has been replicated a number of times, does the accumulated empirical evidence support a negative and statistically significant relationship between property values and air pollution? To address this question, we analyzed the results reported in thirty-seven hedonic property value studies with at least one measure of air pollution. This evaluation is based on qualitative variables defined using the results of tests as to whether

Environmental and Resource Economics 3: 381-394, 1993.

(C) 1993 Kluwer Academic Publishers. Printed in the Netherlands. 
air pollution measures in each of the hedonic models would be judged as statistically significant determinants of property values at different $p$ values (i.e. probabilities of a Type I error).

This paper reports probit analyses of the factors influencing whether each study found a theoretically consistent and statistically significant relationship between air pollution and property values. Our approach builds on previous statistical reviews of empirical literature originally developed in psychology and education (see Glass, 1976; Hedges and Olkin, 1985; and Cordray, 1987) by demonstrating how conclusions drawn from empirical studies can be subjected to econometric analysis. Moreover, it evaluates one aspect of using hedonic methods to estimate the value of nonmarketed environmental resources. ${ }^{1}$

\section{Data, Model, and Results}

The data for this meta analysis of hedonic models were derived from a review of over fifty studies discussing the role of air pollution in hedonic property value models. Our initial screening selected studies that estimated hedonic propety value functions including at least one measure of air pollution. Thirty seven studies (including Ridker and Henning, 1967) provide the basis for our data base (see Appendix A for a listing of the specific citations for each of the studies included). Twenty-six of the studies were published in journals, one in an edited volume, five were unpublished Ph.D. disserations, and five were unpublished papers. Because each study often reported multiple models, the summary statistics for these studies led to 167 observations. Table I summarizes some of the broad features of the sample of estimates used for our analysis, describing the timing of the housing sales, the price measure used, and the number of estimated models reported in each study.

Table I. Features of the sample of hedonic studies

\begin{tabular}{|c|c|c|c|c|c|c|c|}
\hline \multirow{2}{*}{$\begin{array}{l}\text { Year of } \\
\text { Sample }\end{array}$} & \multicolumn{3}{|c|}{ Type of Price Measure } & \multicolumn{4}{|c|}{ Number of Models Reported } \\
\hline & Census & $\begin{array}{l}\text { Actual } \\
\text { Price }\end{array}$ & $\begin{array}{c}\text { Restricted } \\
\text { Price }^{\mathrm{a}}\end{array}$ & $1-5$ & $6-10$ & $11-15$ & $>15$ \\
\hline 1960 & 10 & 2 & - & 9 & 2 & 1 & - \\
\hline $1961-69$ & 5 & - & - & 4 & - & 1 & - \\
\hline 1970 & - & 2 & 3 & 5 & - & - & - \\
\hline $1971-79$ & 1 & 8 & 4 & 9 & 1 & 2 & 1 \\
\hline 1980 & 2 & - & - & 2 & - & - & - \\
\hline
\end{tabular}

${ }^{a}$ Restricted price refers to a sample that has a restricted range of prices, such as the transactions associated with FHA mortgages in a particular city. 
Several factors contributed to reducing the sample used in our summary evaluation of the record from the 167 separate estimates. One of the most important of these issues from the perspective of our analysis concerns the independence of each study's estimates as contributions to our summary. As Table I indicates, it is relatively common for a study to report results for several model specifications (and we describe below how our estimates adjust for the effects of multiple models). In addition, there are several cases where it appears that the same estimated hedonic model (or a very close variation) has been used in different papers to meet different research objectives. In this case, we have attempted to identify the duplication and include only one of these papers. Table II identifies the duplicate uses of the same estimated hedonic models and indicates the particular study selected for our analysis. An equally important source of overlap arises from progressive refinements in databases that can accompany from a long-term program of research. The most notable example of this for the hedonic models in our sample is associated with Palmquist's (1984, 1982 and 1983) research. In this case each study represents a different type of refinement in variables, estimator, or modeling assumptions that have been applied to different subsets of the same basic data set. Because Palmquist's three papers could contribute as much as forty-one estimates to our sample, their treatment can be influential to our findings. The first study in the research sequence, Palmquist (1984), focused on the role of only one pollutant in analyzing the second-stage demand models for housing characteristics using linear hedonic price equations for seven cities. ${ }^{2}$ We included these results in our analysis of the performance of particulate matter as the air pollution measure. Palmquist's second study (1982) included four pollutants (annual second-high reading for total suspended particulates, annual arithmetic mean of nitrogen dioxide, annual second-high reading for ozone, and annual median for sulfur dioxide) for twenty cities. This study was included in the sample analyzing performance of the model with any air pollution measure. ${ }^{3}$ Table III lists the studies that were used for our statistical summary of the performance of air pollution measures in hedonic models, identifying the authors, date (of the study), and the city for each study.

This paper focuses primarily on the conclusions that can be drawn in testing the relationship between the air pollution measure used and property values. We defined two measures to characterize the primary question Ridker and Henning sought to evaluate - the existence of a relationship beween air pollution and property values:

(1) a qualitative variable that is unity if at least one of the air pollution measures in an equation was negative and significantly different from zero with a $p$-value of 0.10 (designated Decision 1 ); and

(2) a qualitative variable defined using a comparable criteria to (1) but focusing on whether this decision would be made exclusively on the 


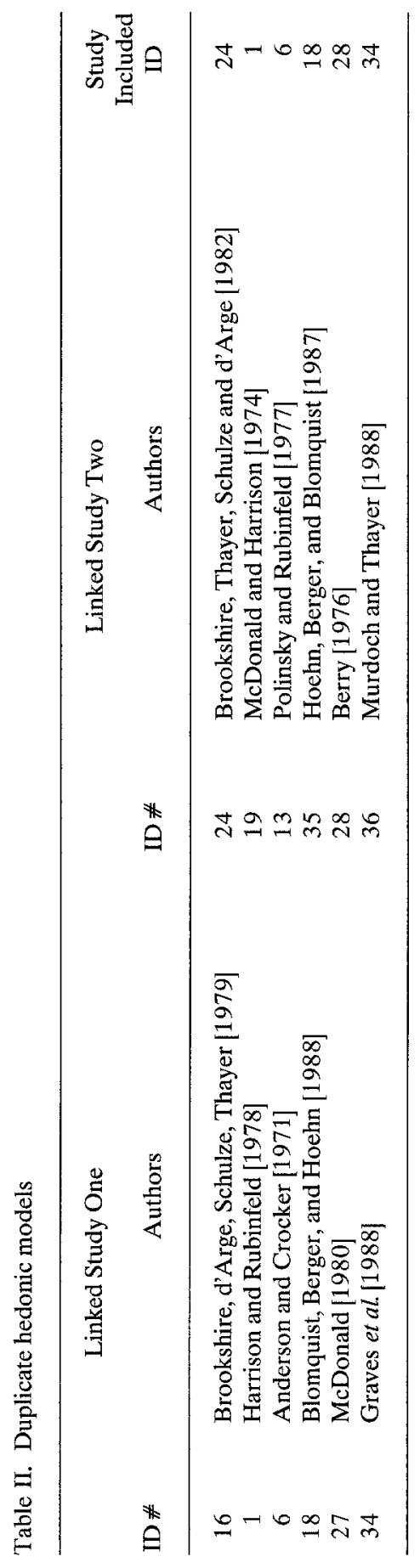


Table III. Studies included in analysis ${ }^{\mathrm{a}}$

\begin{tabular}{rlll}
\hline $\begin{array}{l}\text { Study } \\
\text { ID }\end{array}$ & \multicolumn{1}{c}{ Author } & Year of Study & \multicolumn{1}{c}{ City } \\
\hline 1 & Harrison and Rubenfeld & 1978 & Boston \\
2 & Ridker and Henning & 1967 & St. Louis \\
3 & Bender, Gronberg and Hwang & 1979 & Chicago \\
4 & Wieand & 1973 & St. Louis \\
5 & Nelson & 1978 & Washington, D.C. \\
7 & Smith (Barton) & 1978 & Chicago \\
8 & Krumm & 1980 & Chicago \\
10 & Diamond & 1980 & Chicago \\
11 & Li and Brown & 1980 & Boston \\
14 & Goodwin & 1977 & Boston \\
20 & Palmquist & 1982 & Multiple Cities \\
22 & Atkinson and Crocker & 1982 & Chicago \\
23 & Bresnock & 1981 & Denver \\
24 & Brookshire, Thayer, Schulze, and d'Arge & 1982 & Los Angeles \\
25 & Bender and Hwang & 1985 & Chicago \\
26 & Sonstelie and Portney & 1980 & San Mateo \\
28 & Berry & 1976 & Chicago \\
29 & Jackson & 1979 & Mitwaukee \\
31 & Appel & 1980 & New York \\
32 & Soskin & 1979 & Washington, D.C. \\
33 & Egan & 1973 & Hartford \\
37 & Brucato & 1990 & Los Angeles, San Francisco \\
& & & \\
\hline
\end{tabular}

a This set of studies relates to the sample used for the variable Decision 1 . For the case of Decision 2, the ID numbers for studies are: $1,3,4,5,7,8,11,15,22,24,25,28,29,31,32$, 33,37 .

basis of the estimated parameter in the hedonic price equation for particulate matter (designated Decision 2).

A simple test of the evidence supporting a consistent linkage between prices and air pollution might seem to be testing whether the proportion of models that satisfied each criteria was different than that produced by chance. For Decision 1,74 percent of the models report a negative and significant relationship; while for Decision 2, only 56 percent do so. A test of the difference between these proportions and 50 percent clearly rejects the null hypothesis (the likelihood of accepting or rejecting a consistent linkage between air pollution and property values is equal) with the Decision 1 outcome measure. It does not reject this hypothesis for Decision $2 .{ }^{4}$

Of course, the proportion of models with negative and significant coefficients may not be 50 percent by chance. One could argue that we should have used 10 percent (i.e. the $p$-value used in defining Decision 1 and Decision 2). However, an important selection effect may govern the pub- 
lished studies that compose the majority of our sample. Studies successfully demonstrating the hypothesized link between air pollution and housing prices are probably more likely to be published than those offering inconclusive results. This tendency may be especially pronounced in the early stages of the literature's development. Once enough empirical evidence accumulates to regard the linkage as an "empirical fact," then interest increases in contradictory evidence. (See Graves et al., 1988 as an example.)

Any attempt to use statistical results as "data" for a second stage summary will face this type of selection effect both because negative results (i.e. those contradicting accepted hypotheses are less likely to be published or known) and because the unpublished literature will be more difficult to uncover and represent. To attempt to deal with these limitations, we searched University Microfilms and reviewed all economics (and related) Ph.D. dissertations reported from 1970 through 1990 whose abstracts indicated empirical hedonic models with air pollution. In addition, we investigated the effects of a qualitative variable defined based on whether each study included in our sample had been published on our two dependent variables. This factor distinguishing the studies was not a significant determinant in the models for either dependent variable. ${ }^{5}$

Our evaluation of what has been learned about the relationship between housing prices and air pollution is based on multivariate probit models using each of the decision variables described earlier. Each model included variables describing the data used, model specification features, and city characteristics in each application that might influence the plausibility of the hedonic framework's underlying assumptions. Table IV reports the estimates and the definitions for the specific variables. Because some studies reported multiple estimates that included both different cities (as in the Palmquist

Table IV. Probit models for consistent, statistically significant linkage

\begin{tabular}{lcc}
\hline Independent Variables $^{\mathrm{b}}$ & $\begin{array}{c}\text { Decision 1 } \\
\text { (Any Pollution Variable) }\end{array}$ & $\begin{array}{c}\text { Decision 2 } \\
\text { (Particulate Matter Only) }\end{array}$ \\
\hline Intercept & $-4.43^{*}$ & 6.86 \\
& $(-1.84)[-2.06]^{\mathrm{d}}$ & $(1.07)[1.54]$ \\
Number of Observations & $0.75 \times 10^{-2 * *}$ & $0.41 \times 10^{-2 *}$ \\
& $(2.17)[2.81]$ & $(1.61)[2.20]$ \\
Linear Specifications & $-2.89^{*}$ & $-2.67^{* *}$ \\
$(=1)(-)$ & $(-2.39)[-2.33]$ & $(-2.35)[-3.12]$ \\
Use of Actual Housing Price $(=1)$ & $-3.64^{* *}$ & $-2.26^{+}$ \\
& $(-1.62)[-3.40]$ & $(-0.80)[-1.71]$ \\
Number of Demographic Variables & -0.13 & $-2.75^{* *}$ \\
& $(-0.27)[-0.32]$ & $(-1.97)[-2.43]$
\end{tabular}


Table IV (Continued)

Independent Variables ${ }^{\mathrm{b}}$

Decision 1

Decision 2

(Any Pollution Variable)

(Particulate Matter Only)

Number of Housing Characteristics

$$
0.38^{* * *}
$$

(1.97) [2.88]

Use of OLS $(=1)$

Number of Air Pollutants in

Model (-)

Number of Neighborhood

Characteristics

Geometric Mean of TSP Second

High (+)

Vacancy Rate

Missing Value of Vacancy Rate

Dummy (= 1 if missing)

Measures of Access

$n$

Pseudo $R^{2 \mathrm{c}}$

Proportion Correct
0.78

(0.36) [0.61)

$-1.78^{* *}$

$(-1.77)[-2.70]$

0.46

(0.83) [1.24]

$0.02^{* * *}$

(2.17) [3.04]

$5.47^{* * *}$

(2.23) [3.03]

$-3.51^{\mathrm{km}}$

$(-2.36)[-3.58]$

$-0.67^{+}$

$(-1.41)[-1.69]$

74

0.59

0.92
$-0.39$

$(-1.07)[-1.33]$

$-0.55$

$(-0.18)[-0.43]$

$-5.96 *$

$(-2.34)[-4.05]$

1.01 **

(1.64) [3.58]

0.02

$(0.87)$ [1.12]

$1.56^{+}$

(1.16) [1.87]

$3.11^{* *}$

(1.64) [2.78]

0.72

(1.16) [1.58]

45

0.56

0.80

a The numbers in parentheses below the estimated coefficients are the ratios of the coefficients to their estimated asymptotic standard errors. Using the standard normal, we have identified statistically significant factors with:

$+=$ significantly different from zero; $p=0.10$.

$*$ significantly different from zero; $p=0.05$.

$* *=$ significantly different from zero; $p=0.01$.

b The independent variables are largely self-explanatory. For example, the number of observations is the size of the sample used in each study. For clarification, linear specification refers to the model used in developing the outcome (i.e., Decision 1 or Decision 2). Use of actual price refers to whether the hedonic model used the actual sales price $(=1)$ in comparison with census tract or appraisal values. Use of OLS refers to whether ordinary least squares was used to estimate the hedonic model. Geometric Mean of TSP second highs refers to a separately developed measure of particulate matter for each city at as close to the year of the original sample as possible. Vacancy Rate is used as a measure of local housing market conditions and refers to the rate from the state and metropolitan data for each city in the year available that was closest to the sample year for each city. Because this was not available for about 21 percent of the cities in our study, we used the mean rate for the missing values and included this variable to evaluate the effects of this assumption. Measures of Access corresponds to the number of variables in each model describing accessibility or distance to $\mathrm{CBD}$, major highways, shopping areas, and airports.

c This is calculated as $1-\left(L_{1} / L_{2}\right)$ where $L_{1}$ is the maximum value of the log-likelihood function with all parameters and $L_{2}$ is the function with intercepts only (all other parameters restricted to zero). See McFadden, 1974. 
studies described earlier) and different estimates (several functional forms may have been used for the estimated hedonic price functions), the sample composition could imply a nonspherical error structure and therefore violate the assumption underlying the probit estimator. While we were able to limit these effects somewhat by eliminating duplicate studies and using only one of the Palmquist studies in each sample, the sample cannot be assumed to satisfy the assumption underlying probit. To adjust our tests for the effects of heteroscedasticity, we used Huber's (1967) asymptotic bootstrap method to estimate the covariance matrix for the probit coefficients in each model. ${ }^{6}$ The $Z$ statistics based on these estimated asymptotic standard errors are reported in brackets beside those estimated assuming well-behaved errors. This adjustment strengthens the conclusions that can be drawn from the analysis. Nonetheless, it does not completely address the problems posed by the sample. Cross observation correlation is not reflected in this covariance estimator and could also be an issue with our summary models. Of course, unlike heteroscedasticity, it seems reasonable to assume that this effect is reduced by eliminating duplicate studies.

Overall our estimates indicate that there is a systematic relationship between the modeling decisions, the descriptions used to characterize air pollution, the condition of the local housing markets, and the conclusions reached about the relationship between air pollution and housing prices. In those cases where we can formulate a null hypothesis (indicated with a sign beside the variable name in Table IV), there is generally agreement with $a$ priori expectations when the variable was found to be significant. Where the estimated effects of model characteristics or local conditions is a statistically significant influence on both decision measures, the sign of the effects is consistent.

Some of the most interesting determinants relate to the data used, the functional form, the number of pollution measures and extent of the problem, and the local housing conditions. Use of actual housing sales prices appears to reduce the prospects for detecting significant (and consistent) effects of air pollution when compared with the census aggregates. Here it seems likely that greater variability in actual sales prices makes the estimated models inherently more "noisy" even though the actual price measure would be preferred on theoretical grounds. A linear specification seems to also reduce the prospects for detecting a link. This finding appears consistent with the controlled experiments of Cropper et al. (1988) favoring the more flexible forms over the restrictive linear models, at least in terms of the accuracy of the measures for marginal effects.

It may seem somewhat surprising that more air pollution measures in the model reduces the prospects for finding a significant relationship, even when we use a measure that would count the finding with any one of them a success. The explanation probably lies in the high level of collinearity among air pollution variables. Significant and consistent linkages are associated with 
higher levels of air pollution, as represented here by an independent (of each study's sample) measure of particulate matter at about the time of each study's housing price measures.

Finally, market conditions may be important to the model's performance. The vacancy rate measure (matched for each study's city and approximate year of housing sales) has an influence, but it is difficult to formulate clearcut hypotheses about the direction of this effect. Thus, because of this limitation and the difficulty in developing vacancy measures relevant to each city, this result should be interpreted only as suggestive of an effect for market conditions on the performance of hedonic models in detecting the effects of site specific amenities.

\section{Implications}

Ridker and Henning's paper initiated an important line of research that has documented a negative association between some measures of air pollution and residential property values. Unfortunately, this does not mean that we can use models for estimating the marginal value of improving air quality. Once the connection was accepted by the profession, interest in developing estimated models that could be used to provide this type of information for policy making seemed to decline. The most current data set used in a published hedonic model with air pollution evaluated for a U.S. city was $1980 .^{7}$

Our findings suggest that hedonic models have been successful in supporting a connection between air quality conditions at different residential sites within a city and housing prices. Most of the research did not seek to establish more than this connection. To date there has been less interest in refining estimates of hedonic property value models with air pollution to provide the resolution in the marginal effects that would be required to use the results in estimating people's incremental values for reducing pollution. Instead, policy interest (and empirical modeling) has focused on using the hedonic models for other applications with proxy variables (often difficult to interpret) for the services of environmental resources. Because these applications tend to be more narrowly focused, it is difficut to use them to supplement our evaluation of the hedonic methodology. Based on the evidence available for air pollution, the model has proved successful in detecting the direction of air quality's influence on residential property values.

\section{Notes}

* Partial support for this research was provided by the Russell Sage Foundation. Thanks are due David Cordray, Heidi Hartman, and Larry Hedges of the Foundation's Meta-Analysis Panel for constructive comments, to Ray Palmquist for suggestions and assistance in assem- 
bling the results from his studies, to Rick Freeman and Tom Tietenberg and two anonymous referees for comments on the research, and to Barbara Scott for constructive editing of earlier drafts of this paper.

1 This paper is part of a larger research program that is using meta analysis to evaluate the performance of methods for valuing nonmarketed environmental resources. In a separate paper we evaluate the estimates of the marginal rate of substitution that can be derived from past studies. Appendix A lists the studies reviewed (Smith and Huang, 1993). Several other meta analyses of benefit measures have been conducted. In earlier research (Smith and Kaoru, 1990), the first author used meta analysis with travel cost recreation demand models. More recently, Walsh, Johnson, and McKean (1990) have combined travel cost with contingent valuation studies of recreation sites in a meta analytic summary of adjusted, "best" estimates of the consumer surplus per day. An important distinction between Walsh, Johnson, and McKean approach and the earlier Smith-Kaoru analysis is the somewhat arbitrary adjustments the former authors made to the consumer surplus estimates to account for differences in modeling assumptions.

The most recent application of meta analysis has been completed for some of the contingent valuation studies of people's willingness to pay for visibility improvements (see Smith and Osborne, 1993).

2 The reason for the contradiction in dates when compared with the research sequence is the lag in publication. Completed in 1981, Palmquist (1984) is the only published paper from this research program.

3 Palmquist (1983) sought to refine the measure in the earlier study and attempted to resolve inconsistencies in the estimated effects of air pollution variables. By selecting the earlier study, we include results that are both consistent and inconsistent with a priori theoretical expectations.

${ }_{4}$ These tests use the normal approximation to the binomial with

$$
Z=\frac{X-n \theta}{\sqrt{n \theta(1-\theta)}}
$$

where $X=$ the count of times each decision variable was satisfied;

$\theta=$ the proportion specified for the null hypothesis; and

$n=$ sample size.

The $Z$ statistic was 4.30 for Decision 1 and 0.80 for Decision 2 .

5 The estimates using the Decision 1 measure with a qualitative variable indicating where the study was published are as follows:

$$
\text { Decision } 1=-7.35+0.01 \text { Number of Obs } \quad-2.39 \text { Linear Spec }
$$

-4.47 Use of Actual Price - 0.30 Number of Demographic Variables

$[-2.96] \quad[-0.65]$

+0.36 Number of Housing Characteristics -0.31 Use of OLS

[2.28]

-2.22 Number of Air Pollutants

$[-0.20]$

$[-2.54]$

+0.04 Geometric Mean of TSP

[2.54]

+0.83 Number of Neighborhood Characteristics

[1.16]

+6.78 Vacancy Rate

[3.26]

-4.60 Missing Value of Vacancy Rate $\quad+2.31$ Published $(=1)$

$[-3.21]$

Pseudo $R^{2}=0.61$

The estimated standard errors used for the asymptotic $Z$ statistics in brackets are based on the Huber, 1967 robust covariance estimator. The only substantive change in the model arises in 
the sign of the coefficient for the qualitative variable for use of OLS. It becomes negative but remains insignificant when the published qualitative variable is included.

The sign of the coefficient for "published" is consistent with a priori expectations. However, one might carry the questions further arguing for a two-way causality - a significant, correctly signed effect is necessary for publication. We cannot effectively test this issue because we do not have an inventory of all analyses done to take account of the success and failure in detecting the influence of air pollution.

${ }^{6}$ Huber's, 1967 estimator constructs a weighted covariance estimator relying on the score and Hession of the likelihood function. Let

$$
\sum g\left(x_{t} \beta\right)
$$

designate the log likelihood function ( $X_{t}$ and $\beta$ are conformably dimensioned vectors)

$$
\begin{aligned}
& S_{j}=\frac{\partial g}{\partial\left(x_{j} \beta\right)} \text { is the score } \\
& H_{j}=\frac{\partial^{2} g}{\partial\left(x_{j} \beta\right)^{2}} \text { is the Hessian } \\
& D=\sum_{i} H_{i}\left(x_{i}^{T} x_{i}\right)
\end{aligned}
$$

Then the Huber covariance matrix is defined as:

$$
\operatorname{Var}(\hat{\beta})=D^{-1}\left(\sum_{j} S_{\jmath}^{T} x_{l}^{T} x_{l} S_{\jmath}\right) D^{-1}
$$

7 Schechter, 1991 recently included a linkage between housing and medical services in an expendable model. This study was part of a larger comparison of alternative methods for estimating the value of air quality improvements in Israel that included a hedonic property model, along with contingent valuation, averting costs, and the expenditure share models described in this paper. The hedonic component of the analysis can be found in Shechter and Kim, 1991.

\section{Appendix A}

The numbers in parenthesis identify the ID number for each study,

Anderson, Robert J. Jr. and Thomas D. Crocker (1971), 'Air Pollution and Residential Property Values', Urban Studies 8. (6)

Appel, David (1980), 'Estimating the Benefits of Air Quality Improvement: An Hedonic Price Index Approach Apphed to the New York Metropolitan Area', Rutgers University, $\mathrm{PhD}$ Dissertation. (31)

Atkinson, Scott E. and Thomas D. Crocker (1982), 'A Bayesian Approach to Assessing the Robustness of Hedonic Property Value Studies'. (22)

Bender, Bruce, Timothy J. Gronberg and Hae-Shin Hwang (1979), 'Choice of Functional Form and the Demand for Air Quality', The Review of Economics and Statistics. (3)

Bender, Bruce and Hac-Shin Hwang (1985), 'Hedonic Housing Price Indices and Secondary Employment Centers', Journal of Urban Economics 17. (25)

Berry, Brian J. L. (1976), 'Ghetto Expansion and Single-Family Housing Prices: Chicago, 1968-1972', Journal of Urban Economics 3. (28)

Blomquist, Glenn C., Mark C. Berger and John P. Hoehn (1988 Mar.), New Estimates of Quality of Life in Urban Areas', American Economic Review. (18) 
Bresnock, Anne E. (1981), 'Housing Prices, Income and Environmental Quality in Denver', PhD Dissertation. (23)

Brookshire, David S., R. C. d'Arge, W. D. Schulze, and M. A. Thayer (1979), 'Experiments in Valuing Non-Market Goods: A Case Study of Alternative Benefit Measures of Air Pollution Control in the South Coast Air Basin of Southern California', Chap. 5, Vol II. (16)

Brookshire, David S., Mark A. Thayer, William D. Schulze and Ralph C. d'Arge (1982), 'Valuing Public Goods: A Comparison of Survey and Hedonic Approaches', American Economic Review 72(1). (24)

Brucato, Peter F. Jr., James C. Murdoch and Mark A. Thayer (1990), 'Urban Air Quality Improvements: A Comparison of Aggregate Health and Welfare Benefits to Hedonic Price Differential', Journal of Environmental Management 30, 265-279. (37)

Deyak, Timothy A. and V. Kerry Smith (1974), 'Residential Property Values and Air Pollution: Some New Evidence', Quarterly Review of Economics and Business 14(4). (9)

Diamond, Douglas B. Jr. (1980), "The Relationship Between Amenities and Urban Land Prices', Land Economics 56(1). (10)

Egan, Francis Joseph (1973), 'Air Pollution and Property Values in the Hartford Metropolian Region', Fordham University, PhD Dissertation. (33)

Goodwin, Susan Ann (1977), 'Measuring the Value of Housing Quality - A Note', Journal of Regional Science 17(1). (14)

Graves, Phil, James C. Murdoch, Mark A. Thayer and Don Waldman (1988), 'The Robustness of Hedonic Price Estimation: Urban Air Quality', Land Economics 64(3). (34)

Harrison, David Jr. and Daniel L. Rubinfeld (1978), 'Hedonic Housing Prices and the Demand for Clean Air', Journal of Environmental Economics and Management 5. (1)

Hoehn, John P., Mark C. Berger and Glenn C. Blomquist (1987), 'A Hedonic Model of Interregional Wages, Rents, and Amenity Values', Journal of Regional Science 27(4). (35)

Jackson, Jerry R. (1979), 'Intraurban Variation in the Price of Housing', Journal of Urban Economics 6. (29)

Krumm, Ronald J. (1980), 'Neighborhood Amenities: An Economic Analysis', Joumal of Urban Economics 7. (8)

Li, Mingche M. and H. James Brown (1980), 'Micro-Neighborhood Externalities and Hedonic Housing Prices', Land Economics 56(2). (11)

Mark, Jonathan H. (1980), 'A Preference Approach to Measuring the Impact of Environmental Exernalities', Land Economics 56(1). (12)

McDonald, John F. (1980), 'The Use of Proxy Variables in Housing Price Analysis', Journal of Urban Economics 7. (27)

Murdoch, James C. and Mark A. Thayer (1988), 'Hedonic Price Estimation of Variable Urban Air Quality', Journal of Environmental Economics and Management 15. (36)

National Academy of Sciences (1974), 'Air Quality and Automobile Emission Control', A Report by the Coordinating Committee on Air Quality Studies 4. (19)

Nelson, Jon P. (1978), 'Residential Choice, Hedonic Prices, and the Demand for Urban Air Quality', Journal of Urban Economics 5. (5)

Palmquist, Raymond B (1982), 'Estimating the Demand for Air Quality From Property Value Studies'. (20)

Palmquist, Raymond B. (1983), 'Estimating the Demand for Air Quality From Property Value Studies: Further Results'. (21)

Palmquist, Raymond B. (1984), 'Estimating the Demand for the Characteristics of Housing', Review of Economics and Statistics 66. (15)

Polinsky, A. Mitchell and Daniel L. Rubinfeld, Property Values and the Benefits of Environmental Improvements: Theory and Measurement, Public Economics and the Quality of Life. Edited by Lowdon Wingo and Alan Evans. (13)

Ridker, Ronald G. and John A. Henning (1967 May), 'The Determinants of Residential Property Values With Special Reference to Air Pollution', Rev. Econ. St. 49. (2) 
Smith, Barton A. (1978), 'Measuring the Value of Urban Amenities', Journal of Urban Economics 5. (7)

Smith, V. Kerry and Timothy A. Deyak (1975), 'Measuring the Impact of Air Pollution on Property Values', Journal of Regional Science 15(3). (30)

Sonstelie, Jon C. and Paul R. Portney (1980), 'Gross Rents and Market Values: Testing the Implications of Tiebout's Hypothesis', Journal of Urban Economics 7. (26)

Soskin, Mark D. (1979), 'Detection and Treatment of Multicollinearity With Application to Problems of Estimating Pollution Costs from Housing Market Models', The Pennsylvania State University, $\mathrm{PhD}$ Dissertation. (32)

Spore, Robert L (1972 June), 'Property Value Differentials As a Measure of the Economic Costs of Air Pollution', Center for Air Environment Studies, The Pennsylvania State University, Publication No. 254-72. (17)

Wieand, Kenneth F. (1973) 'Air Pollution and Property Values: A Study of the St. Louis Area', Journal of Regional Science 13(1). (4)

\section{References}

Cordray, David S. (1987), 'Strengthening Causal Interpretations of Non-Experimental Data: The Role of Meta Analysis', in L. Sechrest, J. Bunker and E. Perrin (eds.), Improving Methods in Non-Experimental Research. Menlo Park. CO: Sage Publications.

Freeman III, A. Myrick (1974 May), 'On Estimating Air Pollution Control Benefits From Land Value Studies', Joumal of Environmental Economics and Management 2, 74-84.

Glass, G. V. (1976), 'Primary, Secondary, and Meta-Analysis of Research', Educational Researcher 5(1), 3-8.

Graves, Phil, James C. Murdoch, Mark A. Thayer and Don Waldman (1988 Aug), 'The Robustness of Hedonic Price Estimation: Urban Air Quality', Land Economics 64, 220233.

Hedges, L. V. and I. Olkin (1985), Statistical Methods for Meta Analysis. New York: Academic Press.

Hendry, David F. (1983 Nov), 'Econometric Modeling: The 'Consumption Function' in Retrospect', Scottish Journal of Political Economy 30, 193-220.

Huber, P. J. (1967), 'The Behavior of Maximum Likelihood Estimates Under Non-Standard Conditions', Proceedings of the Fifth Symposium on Mathematical Statistics and Probability, University of California Press, 221-233.

McFadden, Daniel (1974), 'The Measurement of Urban Travel Demand', Journal of Public Economics 3, 303-328.

Nakamura, A. O., M. Nakamura and H. O. Duleep (1990), 'Alternative Approaches to Model Choice', Journal of Economic Behavior and Organization 14, 97-125.

Palmquist, Raymond B. (1982), 'Estimating the Demand for Air Quality From Property Value Studies', unpublished paper, Department of Economics, North Carolina State University.

Palmquist, Raymond B. (1983), 'Estimating the Demand for Air Quality From Property Value Studies: Further Results', unpublished paper, Department of Economics, North Carolina State University.

Palmquist, Raymond B. (1984), 'Estimating the Demand for the Characteristics of Housing', Review of Economics and Statistics 66, 394-404.

Ridker, Ronald G. and John A. Henning (1967 May), 'The Determinants of Residential Property Values With Special Reference to Air Pollution', Review of Economics and Statistics 49, 246-257.

Rosen, Sherwin (1974), 'Hedonic Prices and Implicit Markets', Journal of Political Economy 82, 34-35.

Shechter, Mordechai (1991 Nov), 'A Comparative Study of Environmental Amenity Valuations', Environmental and Resource Economics 1, 129-155. 
Shechter, Mordechai and M. Kim (1991 Sept), 'Valuation of Pollution Abatement Benefits: Direct and Indirect Measurement', Journal of Urban Economics 30, 133-151.

Smith, V. Kerry and Ju Chin Huang (1993 Feb), 'Can Hedonic Models Value Air Quality? A Meta-Analysis', Resource and Environmental Economics Program, North Carolina State University, revised.

Smith, V. Kerry and Yoshiaki Kaoru (1990 May), 'Signals or Noise? Explaining the Variation in Recreation Benefit Estimates', American Journal of Agricultural Economics, 419-433.

Smith, V. Kerry and Laura Osborne (1993 Feb), 'Do Contingent Valuation Estimates Inform Environmental Policy?: Visibility Changes at National Parks', Resource and Environmental Economics Program, North Carolina State University, paper under revision.

White, H. (1980), 'A Heteroscedasticity-Consistent Covariance Matrix Estimator and a Direct Test for Heteroscedasticity', Econometrica 48, 817-830. 